\section{Commentary: The best is not (always) the enemy of the good}

\author{
Amedeo Anselmi, $\mathrm{MD}, \mathrm{PhD}$, and \\ Jean-Philippe Verhoye, MD, $\mathrm{PhD}$
}

Supracoronary replacement (SCR) with native-valve preservation has been traditionally considered as the reference operation for acute aortic dissection involving the ascending aorta; it represents the more frequently employed strategy in the International Registry of Acute Aortic Dissection registry. ${ }^{1}$ The current paper by Ikeno and colleagues $^{2}$ has the worth to perform a follow-up (median 3.7 years) of 339 patients free from genetic disease and affected by Stanford type A acute aortic dissection and to focus on the late evolution of the repaired aortic root after SCR. This scientific purpose is totally aligned with the contemporary emphasis on the evaluation of late results and durability of adult cardiac surgical operations. Most importantly, the current research has the availability of sufficient clinical/anatomical details to search for predictors of worse root-related outcomes (Valsalva diameter, extension of dissection into the root formalized through the number of involved valve commissures, etc) with a granularity of data that major registries unfortunately do not possess. ${ }^{1}$

To obtain displayable results from this single-center cohort, the authors were obliged to employ a composite follow-up endpoint mixing up death related with the aortic root and root-related reoperation. Methodologically, it must be emphasized that root-related events (dilatation, pseudoaneurysm, valve regurgitation, etc) associated with neither death nor reoperation should be also considered, as they significantly participate to the procedure outcomes. The incidence of such events remains probably important, as many surgeons may refrain from proposing reoperation on the root after previous dissection, given remarkable reoperative risk (anatomical complexity).

The operative mortality for the repair of acute type A dissection is significantly decreasing from previous decades. ${ }^{1}$ The reasons for such encouraging finding are multiple, and they are associated with an evolution in all

From the Division of Thoracic and Cardiovascular Surgery, Pontchaillou University Hospital, Rennes, France.

Disclosures: Authors have nothing to disclose with regard to commercial support.

Received for publication Nov 6, 2019; revisions received Nov 6, 2019; accepted for publication Nov 6, 2019; available ahead of print Nov 27, 2019.

Address for reprints: Amedeo Anselmi, MD, PhD, Division of Thoracic and Cardiovascular Surgery, Pontchaillou University Hospital, Rennes, France (E-mail: amedeo.anselmi@chu-rennes.fr).

J Thorac Cardiovasc Surg 2021;161:494-5

$0022-5223 / \$ 36.00$

Copyright (c) 2019 by The American Association for Thoracic Surgery

https://doi.org/10.1016/j.jtcvs.2019.11.014

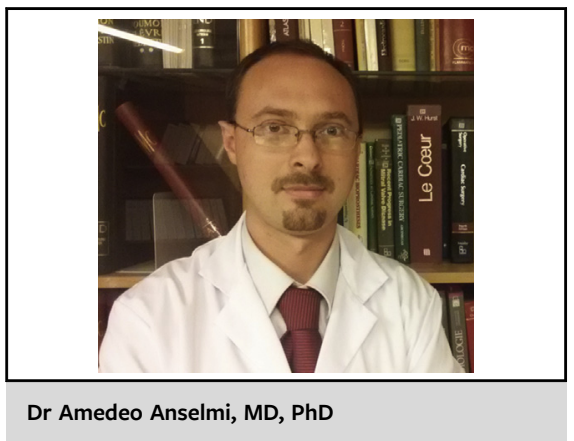

CENTRAL MESSAGE

Root replacement in type $A$

acute aortic dissection is a

powerful means to guarantee

both immediate and late patient

safety when justified by markers

of anatomical aggressiveness of

the disease.

aspects of the operative management of aortic dissection and are not confined to root management. They spring from improvement in both surgical techniques (reproducibility of circulatory arrest for effective distal repair, consolidated expertise in root replacement, potential for arch/downstream aorta treatment) and materials (grafts facilitating hemostasis, surgical glue respectful of tissues). By the way, this article confirms common awareness about the drawbacks of gelatin-resorcin-formalin glue and the need to avoid it in aortic surgery. Therefore, the high level of technological and technical standardization currently available in aortic centers nowadays demands that no inadequate operation associated with the risk of immediate or later degradation of result is performed at the place of a curative operation (root replacement), which is safe in expert hands (it is not associated with increased operative mortality vs SCR in the International Registry of Acute Aortic Dissection ${ }^{1}$ ). This is true even in the context of emergent surgery for a life-threatening condition. Saving the patient's life is indeed the primary objective of surgery for type A dissection; yet, root replacement in the appropriate circumstances must now be considered necessary to fulfill this objective, as it has also the capacity to protect from operative mortality when the root is severely fragile due to dissection or dilatation. We do not know the rate of root-related deaths (due to bleeding or persisting coronary malperfusion) within the pool of operative mortality cases; 
yet, inadequate employment of SCR is likely at their origin and would deserve additional insights.

In summary, the current work has the merit to stimulate reflection and help surgeons facing type A aortic dissection to discriminate cases in which the best is actually the true friend of the good.

\section{References}

1. Evangelista A, Isselbacher EM, Bossone E, Gleason TG, Eusanio MD, Sechtem U, et al. Insights from the International Registry of Acute Aortic Dissection: a 20-year experience of collaborative clinical research. Circulation. 2018;137:1846-60.

2. Ikeno Y, Yokawa K, Yamanaka K, Inoue T, Tanaka H, Okada K, et al. The fate of aortic root and aortic regurgitation after supracoronary ascending aortic replacement for acute type A aortic dissection. J Thorac Cardiovasc Surg. 2021;161: 483-93.e1.
See Article page 483 .

\section{Commentary: Acute type A dissection - Should we systematically replace the aortic root?}

\author{
Jean Bachet, MD, FEBCTS
}

In their article in this issue of the Journal, "The Fate of Aortic Root and Aortic Regurgitation After Supracoronary Ascending Aortic Replacement for Acute Type A Aortic Dissection," Ikeno and coworkers ${ }^{1}$ analyze the evolution of the aortic root and the rates of reoperations or adverse events in this aortic segment in a large cohort of patients operated on during a 20-year period. Their report is based on a large cohort of patients, and the immediate as well as long-term results can be estimated as satisfactory (in-hospital mortality, $13 \%$; late survivals, $87 \%$ at 5 years and $65 \%$ at 10 years). The rates of absence of adverse events in the aortic root were $75 \%$ at 5 years and $57 \%$ at 10 years. These results seem acceptable. Nevertheless, they mean that among the patients surviving surgery, a quarter at 5 years and almost half at 10 years had died or needed to be reoperated on because of an adverse event in the aortic root.

This raises a major and still unresolved question in the great majority of patients. When should the aortic root be replaced?

This question has been resolved for all patients with any connective tissue disease, in particular Marfan syndrome. For those patients, it is now, without any question, largely demonstrated that the aortic root should be systematically replaced, whatever its condition and dilatation. ${ }^{2,3}$ In this

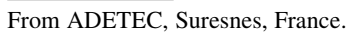

Disclosures: Author has nothing to disclose with regard to commercial support.

Received for publication Nov 16, 2019; accepted for publication Nov 18, 2019; available ahead of print Dec 9, 2019.

Address for reprints: Jean Bachet, MD, FEBCTS, ADETEC, 1 Place Marcel Legras,

92150 Suresnes, France (E-mail: jean.bachet@yahoo.fr).

J Thorac Cardiovasc Surg 2021;161:495-6

$0022-5223 / \$ 36.00$

Copyright (c) 2019 by The American Association for Thoracic Surgery

https://doi.org/10.1016/j.jtcvs.2019.11.084

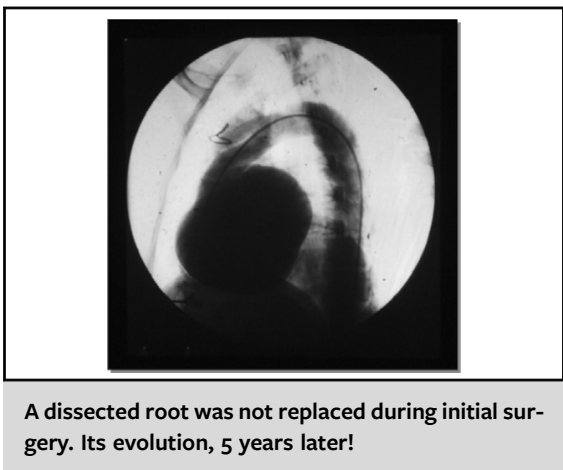

CENTRAL MESSAGE

The main aim of surgery of acute

type A dissection is to save the

patient's life. Yet, a second aim is

to prevent late severe aortic

adverse events. Could then re-

placing the aortic root be

mandatory?

matter, the increasing use of valve sparing procedures is indeed a major progress.

But for the rest of the patients?

On the basis of their study, Ikeno and coworkers ${ }^{1}$ conclude that the initial diameter of the Valsalva sinuses, the number of cusps detached and the use of gelatinresorcinol-formalin glue were independent factors of late aortic root adverse events. This is not really surprising.

The diameter of the Valsalva sinuses is certainly an important determinant if we consider that according to the Laplace law the importance of the wall stress increases with the diameter. Late dilatation, false aneurysm, or even rupture can, however, be observed in patients with a root that is normal or only slightly dilated preoperatively. Indeed, when the aortic root is kept either untouched or just repaired, the wall stress is also linked postoperatively to the thickness or fragility of the Valsalva wall, the ignored 